Journal of Environmental Sciences (JES)

Institute of Environmental Studies and Research, Ain Shams University

Abd Rabu, Nermeen et al.

\title{
EVALUATION OF SOURCES OF POLLUTION IN HEALTH CARE UNITS
}

\author{
Nermeen K. Abd Rabo ${ }^{(1)}$; Mahmoud A. Hewehy ${ }^{(2)}$ \\ Ahmed M. Ahmed ${ }^{(3)}$ \\ 1) Cairo Scan 2) Institute of Environmental Studies and Research, Ain Shams \\ University 3) Ghamra Military Hospital
}

\begin{abstract}
Active surveillance cultures (ASCs) are universal or targeted microbiological screening cultures for patients admitted to a hospital. Healthcare associated infections (HCAIs) are a major health problem worldwide. Inanimate surfaces and equipment contamination may play a role in cross-transmission of pathogens and subsequent patient colonization or infection. Bacteria contaminate inanimate surfaces and equipment of the patient zone and healthcare area, generating a reservoir of potential pathogens, including multidrug resistant species. Traditional terminal cleaning methods have limitations. Indeed patients who receive a bed from prior patient carrying bacteria are exposed to an increased risk of being colonized and potentially infected by the same bacterial species of the previous patient., even on dry surfaces, may play a role in reducing the efficacy of terminal cleaning procedures since it enables bacteria to survive in the environment for a long period and provides increased resistance to commonly used disinfectants. This study aimed to: explore prevalence of bacteria in different isolated samples from various departments. To identify the risk factors associated with gram negative bacilli and gram positive gram positive cocci colonization in both patients and healthcare personnel (HCP). And to assess the association between surface contamination, HCP colonization and patients colonization. This cross-sectional study was conducted in the year 2017 in the period between one April and 31 September, on 66 healthcare personnel (HCP) and 460 patients within 24 hours of admission, age ranged from one day to 85 years old, 1270


surveillance cultures (SC) were received at the microbiology department at a hospital in Cairo. The response rates of this study were $77.5 \%$ of patients and $50 \%$ of $\mathrm{HCP}$.

The HCP and patients swabs' results showed that the two most infectious departments were Gynaecology and Obstetrics, Intensive Care Unit (ICU) followed by Neonate Intensive Care Unit then the least infectious department compared to the previous departments was Surgery departments. The results of environmental swabs showed that $70 \%$ of gram positive bacteria including Methicillin Resistant Staphylococcus Aureus (MRSA) were monitored on Surgery department beds. The prevalence of gram negative bacilli and gram positive cocci carriage is $(53.7 \%$ of patients and HCP). Monitoring and eradication of MRSA and Extended Spectrum Beta Lactamase (ESBL) producing bacteria from patients and HCP should be considered to prevent continuous spread between healthcare facilities and the community.

Keywords: Healthcare associated infections, MRSA, ESBL, gram negative bacteria, surveillance and antimicrobial susceptibility.

\section{INTRODUCTION}

The Center for Disease Control and prevention (CDC) defines HCAIs as infections acquired while in the health care setting (e.g., inpatient hospital admission, hemodialysis unit, or same-day surgery), with a lack of evidence that the infection was present or incubating at the time of entry into the health care setting, These definitions need to respond to a changing medical environment. Modern medical care has become more invasive and therefore associated with a greater risk of infectious complications (Horan, et al., 2008).

HCAIs are infections that patients acquire while receiving treatment for medical or surgical conditions and are the most frequent adverse event during 
Journal of Environmental Sciences (JES)

Institute of Environmental Studies and Research, Ain Shams University

Abd Rabu, Nermeen et al.

care delivery (Bates, 2009). HCAIs is a major problem for patient safety and its impact can result in prolonged hospital stay, long-term disability, increased resistance of microorganisms to antimicrobial agents, a massive additional financial burden for the health system, high costs for patients and their families, and excess deaths (Burke, 2003).

The risk to acquire HCAIs is universal and pervades every health-care facility and system worldwide, but the true burden remains unknown in many nations, particularly in developing countries (Allegranzi, 2011). HCP should be aware of the role of environmental contamination in hospital and consider it in the broader perspective of infection control measures and stewardship initiatives. A gram negative bacilli has long been recognized as important pathogen in hospitalized patients and has severe consequences, despite antibiotic therapy. Hospitalized patients are often immune-compromised, they undergo invasive examinations, treatments, and patient care practices. Hospital environment may facilitate the transmission of microorganisms among patients who are immunosuppressed, and this increases their susceptibility to infection. The nasal and axilla carriage of gram negative bacilli patients or gram positive cocci patients is significant not only in terms of predisposing to subsequent infections, but also in playing an important role in transmission among units staff nasal, axilla and hands and their family members. This study aimed to explore source of isolation, the prevalence of nasal, axilla and hand carriage among surfaces touched by healthcare personnel, the prevalence of nasal, axilla, wound, bedsore carriage among 
Journal of Environmental Sciences (JES)

Institute of Environmental Studies and Research, Ain Shams University

Abd Rabu, Nermeen et al.

patients in ICU, neonate intensive care unit, surgery department and the prevalence of vaginal, rectal and urine carriage among women of gynaecology and obstetrics department.

The study on the efficacy of nosocomial infection control (SENIC) demonstrated that four components were essential to an effective infection prevention and control program. These included: (I) surveillance with feedback of infection control rates to hospital staff, (II) enforcement of preventative practices, (III) a supervising to collect and analyze surveillance data, and (IV) the involvement of a physician or microbiologist with specialized training in infection prevention and control. Programs with these elements reduced rates of the four most common HCAIs by $32 \%$.

Simple interventions such as hand hygiene, environmental cleaning and the appropriate use of barriers such as gowns and gloves have been shown to be quite effective in limiting the spread of bacteria and viruses in healthcare settings. Similarly, other uncomplicated interventions such as "practice bundles" have been shown to decrease infections resulting from mechanical ventilation, surgery and central intravenous catheters. Yet, getting HCP to become interested and consistently comply with these interventions has been shown to be remarkably difficult. (Festary, et al., 2015).

A high frequency of HCAIs is evidence of a poor quality of health service delivery, and leads to avoidable costs. Many factors contribute to the frequency of nosocomial infections: hospitalized patients are often immunocompromised, they undergo invasive examinations and treatments, 146 
Journal of Environmental Sciences (JES)

Institute of Environmental Studies and Research, Ain Shams University

Abd Rabu, Nermeen et al.

and patient care practices and the hospital environment may facilitate the transmission of microorganisms among patients. The selective pressure of intense antibiotic use promotes antibiotic resistance. The most frequent HCAIs are infections of surgical wounds, urinary tract infections and lower respiratory tract infections. The world health organization (WHO) study, and others, has also shown that the highest prevalence of HCAIs occurs in ICU and in acute Surgical and Orthopedic wards. Infection rates are higher among patients with increased susceptibility because of old age, underlying disease, or chemotherapy (WHO, 2002). A new emphasis on HCAIs as a patient safety and public health problem has underscored the need for systematic HCAIs surveillance as part of a broad-based prevention and control strategy (Leape and Berwick, 2005 and Leape, 2002). Benchmark rates were published for inter-hospital comparison. Risk factors for HCAIs vary according to the type of health-care setting and to the care area where the patient is admitted, and are partially different in developing countries. In studies conducted hospital-wide in high-income countries, the most common factors independently associated with HCAIs occurrence were: age more than 65 years; admission as an emergency and to the ICU; hospital stay longer than 7 days; indwelling urinary catheter, placement of a central venous catheter, or an endotracheal tube; trauma-induced immunosuppression; undergoing surgery; neutropenia; impaired functional or coma status and a rapidly or ultimately fatal disease (Gravel, 2007 and Lanini, et al., 2009). The same risk factors were identified in acute-care settings in middle-income 
Journal of Environmental Sciences (JES)

Institute of Environmental Studies and Research, Ain Shams University

Abd Rabu, Nermeen et al.

and low-income countries with the addition of other determinants that are associated with poverty, such as a lack of basic hygiene and limited resources. These include malnutrition, age less than one year, low birth weight, parenteral nutrition, or two or more underlying diseases (De Gentile, 2001 and Cevik, 2005).

\section{MATERIAL AND METHODS}

Methods: The study was conducted at a specific hospital which will remain anonymous for privacy considerations and it will be referred to as Regional Hospital. One of 300 beds hospital, and tertiary care medical center. Hospital serving a county area with a population of approximately more than 20,000. The hospital is a non-profit hospital provides inpatient and outpatient residing in more than seven surrounding countries healthcare services with specialized staff and equipment patients.

All subjects admitted to the hospital who received more than $48 \mathrm{~h}$ of treatment of an infection due to a gram negative bacilli and gram positive cocci which some of them defined as resistant to agents from more than 3 classes of antibiotics. Isolation precautions were used only after multi-drug resistant organisms' colonized patients were detected.

Study Design: All the surveillance cultures included in this study were sent for microbiological detection of MRSA and ESBL from one April 2017 to 31 September 2017. 
Journal of Environmental Sciences (JES)

Institute of Environmental Studies and Research, Ain Shams University

Abd Rabu, Nermeen et al.

Sampling: Samples of $66 \mathrm{HCP}$ and 460 patients within 24 hours of admission taken as nasal, axillary and skin among HCP and other samples are nasal, axillary, wound, bedsore, vaginal, rectal, urine among patients. The Patient's environment between 10 and 25 different sites likely to be touched by patient and/or staff hands were sampled in each room.

For each patient from various departments and ICU who was screened for the gram negative bacilli and gram positive cocci carriage, we got the surveillance swabs from one or more anatomic sites (Nose, throat, skin, vaginal, rectum, groin, arm, oropharynx, and open wounds).

Cultures from body sites and from environmental surfaces were obtained daily from all newly admitted patients in our medical care units (MCU).

Obtain samples of cultures to detect and identify infections, the samples were transported to the microbiology department within one hour of collection to prevent drying the swabs. Swabs were immediately inoculated on macconkey agar and blood agar. Culture: isolation of infectious agents, microbial analysis: plates were incubated at $\sim 37^{\circ} \mathrm{C}$ for $\sim 48-72 \mathrm{~h}$. After incubation, The organism were identified as commensal or pathogen according to microbiological protocol single or mixed growth isolated from the sample were identifying by observing colony character on bacteriological media, photographs were taken to document the appearance and morphology of the colonies, as well as determine sensitivity to antibiotics. Drug resistance was examined with various antimicrobial drugs by the standard disc diffusion 
method (kirby bauer technique) (using inhibition zone criteria for identification of microorganism specific antibiotic resistance). The results from cultures usually take 48 to 72 hours. Treatment based on the location. Then check if we are to achieve results never before accomplished. Check the true or false Improvement.

\section{RESULTS}

In the year 2017 this cross-sectional study was conducted in the period between one April and 31 September, on $66 \mathrm{HCP}$ and 460 patients within 24 hours of admission, Age ranged from one day to 85 years old, 1270 surveillance cultures (SC) were received at the microbiology department.

Table (1): Total no. of surveillance cultures from personnel and patients

\begin{tabular}{|c|c|c|c|c|c|c|c|c|c|}
\hline \multirow[b]{2}{*}{ Month } & \multicolumn{9}{|c|}{ Sources of isolation } \\
\hline & 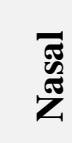 & $\stackrel{\frac{\pi}{7}}{\frac{\pi}{4}}$ & \begin{tabular}{l}
$\widetilde{Z}$ \\
\multirow{Z}{*}{}
\end{tabular} & 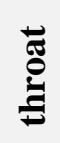 & 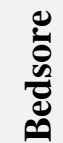 & 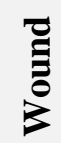 & 苟 & స్త్ర & $\stackrel{\Xi}{\Xi}$ \\
\hline April & 118 & 118 & 66 & - & 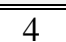 & 3 & 26 & 26 & 26 \\
\hline May & 43 & 43 & - & - & - & 1 & 21 & 21 & 21 \\
\hline June & 59 & 59 & - & 3 & - & 2 & 15 & 15 & 15 \\
\hline July & 77 & 77 & - & - & 3 & 6 & 18 & 18 & 18 \\
\hline August & 61 & 61 & - & - & 5 & - & 18 & 18 & 18 \\
\hline September & 47 & 47 & - & - & 2 & 1 & 23 & 23 & 23 \\
\hline Total & 405 & 405 & 66 & 3 & 14 & 14 & 121 & 121 & 121 \\
\hline
\end{tabular}


Abd Rabu, Nermeen et al.

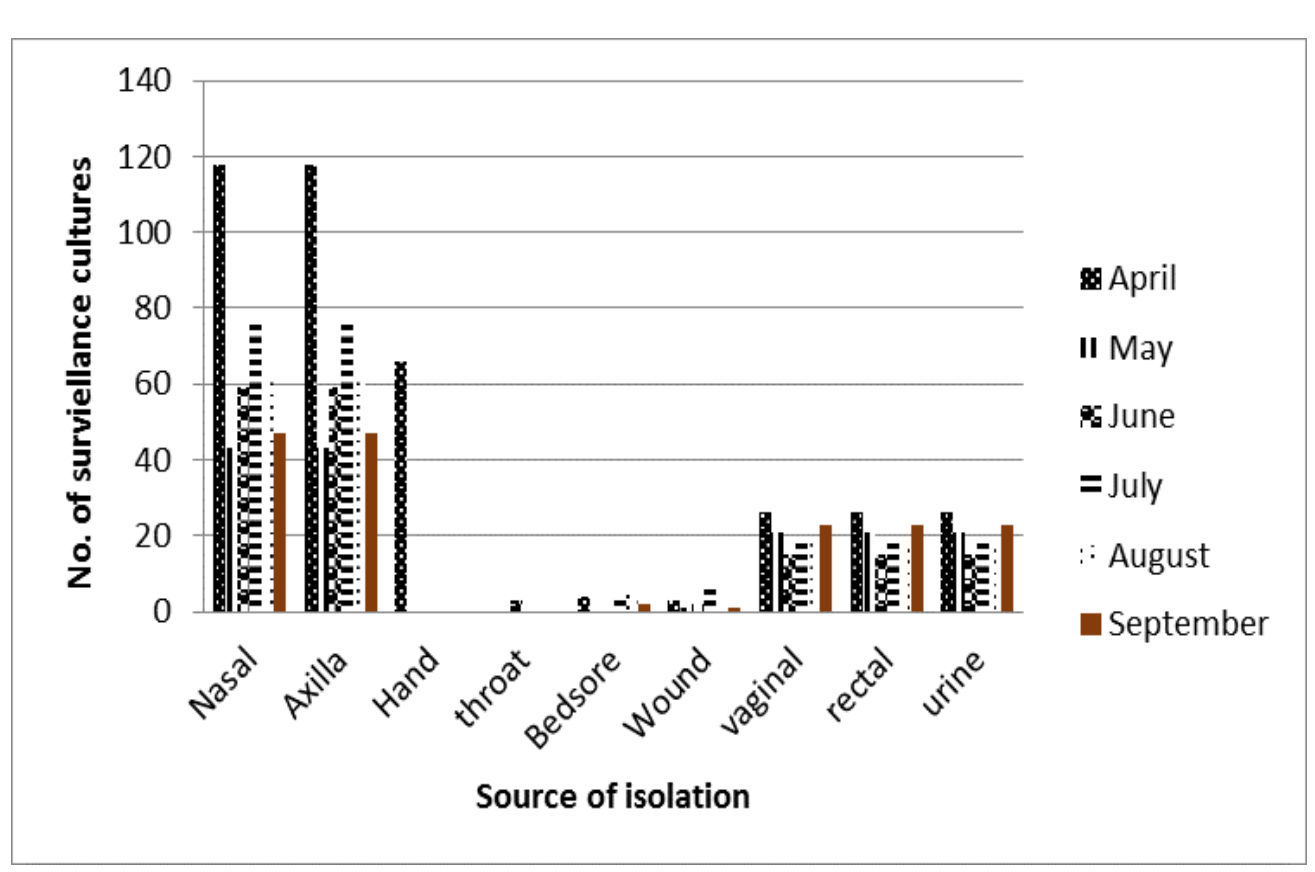

Figure (1): Total number for sources of isolation among the duration of the study

Nasal and axilla swabs were taken by default from patients within 24 hours of admission. In the case of wound, bedsore, sputum...etc., we take the swab. For Gynaecology and Obstetrics department (GOD), the pregnant women (from 35-37 weeks of gestation) enrolled in this study who had paired vaginal, rectal and urine cultures. 
Journal of Environmental Sciences (JES)

Institute of Environmental Studies and Research, Ain Shams University

Abd Rabu, Nermeen et al.

Table (2): Total no. of classification of surveillance cultures

\begin{tabular}{|c|c|c|}
\hline Source of Isolation & Classification & Total No. \\
\hline \multirow{2}{*}{ Nasal } & Gram negative bacilli & 213 \\
\hline & Gram positive cocci & 192 \\
\hline \multirow{2}{*}{ Axilla } & Gram negative bacilli & 249 \\
\hline & Gram positive cocci & 156 \\
\hline \multirow{2}{*}{ Hand } & Gram negative bacilli & 28 \\
\hline & Gram positive cocci & 38 \\
\hline \multirow{2}{*}{ Throat } & Gram negative bacilli & 3 \\
\hline & Gram positive cocci & - \\
\hline \multirow{2}{*}{ Bedsore } & Gram negative bacilli & 14 \\
\hline & Gram positive cocci & - \\
\hline \multirow{2}{*}{ Wound } & Gram negative bacilli & 13 \\
\hline & Gram positive cocci & 1 \\
\hline \multirow{2}{*}{ Vaginal } & Gram negative bacilli & 46 \\
\hline & Gram positive cocci & 75 \\
\hline \multirow{2}{*}{ Rectal } & Gram negative bacilli & 39 \\
\hline & Gram positive cocci & 82 \\
\hline \multirow{2}{*}{ Urine } & Gram negative bacilli & 16 \\
\hline & Gram positive cocci & 105 \\
\hline \multirow{2}{*}{ Total } & Gram negative bacilli & 621 \\
\hline & Gram positive cocci & 649 \\
\hline
\end{tabular}


Abd Rabu, Nermeen et al.

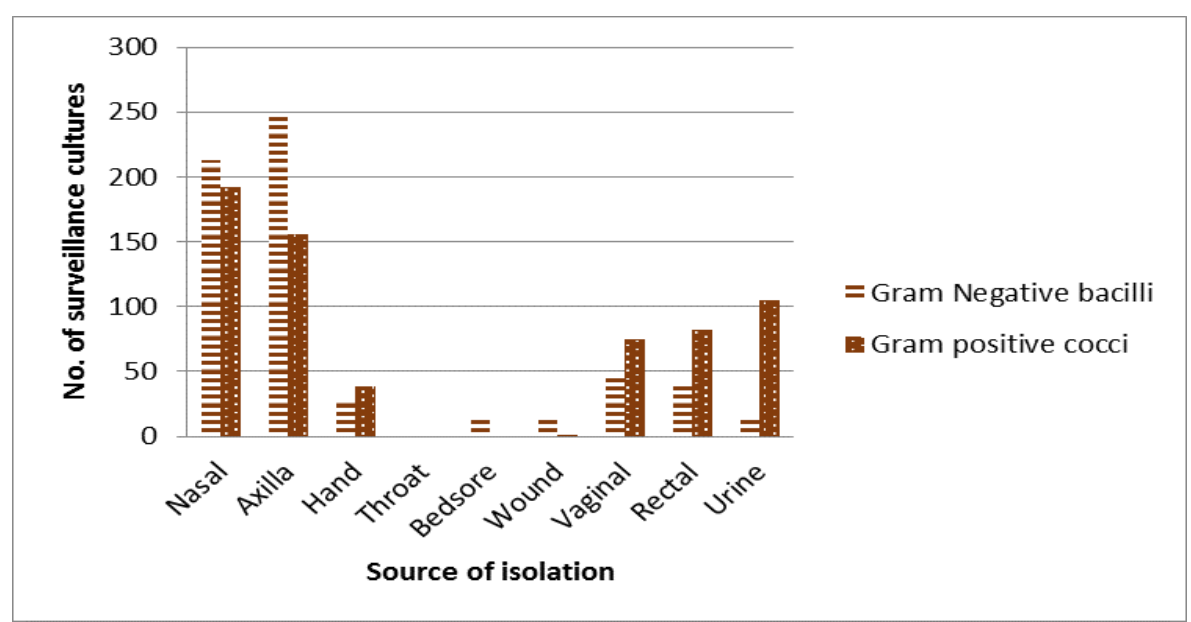

Figure (2): the total number source among the duration of the study

Taking in consideration the special cases and the default of taking the nasal and axilla swabs, the graph represents the total numbers at the end of study.

The number of the categories showed that of $66 \mathrm{HCP}$ chosen from the most common infectious departments where the cases are more vulnerable than others which represent the staff of each department: workers of ICU, workers of Neonatal Intensive Care Unit (NICU), workers of Surgery department (SD), workers of Gynaecology and Obstetrics Department (GOD), workers of laboratory department (LAB) and workers of sterilization department (SD). (36 females, 30 males) were monitored. The bacterial contamination were recovered from HCP nasal, axilla and hands, we find that (46\% of males and $51 \%$ of females). 
Journal of Environmental Sciences (JES)

Institute of Environmental Studies and Research, Ain Shams University

Abd Rabu, Nermeen et al.

Table (3): The type and number of surveillance cultures (SC) Taken from HCP sent for the detection

\begin{tabular}{|c|c|c|c|c|c|c|c|c|}
\hline \multirow{2}{*}{ HCW Samples } & \multirow{2}{*}{$\begin{array}{l}\text { Source of } \\
\text { Isolation }\end{array}$} & \multirow{2}{*}{$\begin{array}{l}\text { Total No. } \\
\text { of HCP }\end{array}$} & \multicolumn{2}{|c|}{ Gender } & \multirow{2}{*}{ classification } & \multicolumn{2}{|c|}{ Gender } & \multirow{2}{*}{ Total } \\
\hline & & & Male & Female & & Male & Female & \\
\hline \multirow{6}{*}{$\begin{array}{l}\text { Workers of } \\
\text { intensive Care unit } \\
\text { (ICU) }\end{array}$} & \multirow{2}{*}{ Nagal } & \multirow{6}{*}{18} & \multirow{6}{*}{9} & \multirow{6}{*}{9} & Gram negrtive becall & 3 & 9 & 14 \\
\hline & & & & & Gram positive cocal & 4 & - & 4 \\
\hline & \multirow{2}{*}{ Axillary } & & & & Gram negative becilli & 3 & 9 & 12 \\
\hline & & & & & Gram postive coccl & 0 & - & 0 \\
\hline & \multirow{2}{*}{ hand } & & & & Gram negative becilli & 3 & 9 & 12 \\
\hline & & & & & Gram posthve coccl & $\sigma$ & - & 0 \\
\hline \multirow{6}{*}{$\begin{array}{c}\text { Workers of } \\
\text { neonatal intensive } \\
\text { care unit (NICU) }\end{array}$} & \multirow{2}{*}{ Nagal } & \multirow{6}{*}{8} & \multirow{6}{*}{4} & \multirow{6}{*}{4} & Gram negative becilli & - & - & - \\
\hline & & & & & Gram posstive coccl & 4 & 4 & 8 \\
\hline & \multirow{2}{*}{ Axillary } & & & & Gram negative becilli & - & - & - \\
\hline & & & & & Gram positive coccl & 4 & 4 & 8 \\
\hline & \multirow[b]{2}{*}{ hand } & & & & Gram negative becilli & - & - & - \\
\hline & & & & & Gram posstive coccl & 4 & 4 & 8 \\
\hline \multirow{6}{*}{$\begin{array}{l}\text { Workers of } \\
\text { surgery } \\
\text { department (SD) }\end{array}$} & \multirow{2}{*}{ Nagal } & \multirow{6}{*}{10} & \multirow{6}{*}{5} & & Gram negative becilli & 3 & 4 & 7 \\
\hline & & & & & Gram positive coccl & 2 & $T$ & 3 \\
\hline & & & & 5 & Gram negative becilli & 2 & 5 & 7 \\
\hline & Agallary & & & 2 & Gram postive coccl & 3 & - & 3 \\
\hline & & & & & Gram negative becilli & 4 & 5 & 9 \\
\hline & hand & & & & Gram positive coccl & $T$ & - & $T$ \\
\hline & & & & & Gram negative becilli & 3 & 3 & 6 \\
\hline Workers of & Nazal & & & & Gram postive coccl & 3 & $T$ & 5 \\
\hline Gynaecology and & A rillyr & 11 & 6 & 5 & Gram negative becilli & 3 & 4 & 7 \\
\hline department & Axillary & 11 & & & Gram postive coccl & 3 & $T$ & 4 \\
\hline & & & & & Gram negative becilli & 3 & 4 & 7 \\
\hline & hand & & & & Gram positive coccl & 3 & $T$ & 4 \\
\hline & Nagl & & & & Gram negative bacilli & - & - & - \\
\hline & Nabal & & & & Gram positive coccl & 2 & 10 & II \\
\hline Laboratory & A villarx & 12 & 2 & 10 & Gram negative becilli & - & - & - \\
\hline department & Apullary & 12 & & & Gram postive coccl & 2 & 10 & III \\
\hline & hond 4 & & & & Gram negative becilli & - & - & - \\
\hline & hand & & & & Gram positive coccl & 2 & 10 & 12 \\
\hline & Nanol & & & & Gram negative becilli & - & - & - \\
\hline & Nabal & & & & Gram postive coccl & 4 & 3 & $T$ \\
\hline Workers of & Axillary & 7 & 4 & 3 & Gram negative becilli & - & - & - \\
\hline department & Ayluary & $f$ & & & Gram positive coccl & 4 & 3 & $T$ \\
\hline & hand & & & & Gram negative becilli & - & - & - \\
\hline & & & & & Gram postive coccl & 4 & 3 & $T$ \\
\hline To & & & 66 & & Gram positive coccl & & III? & \\
\hline
\end{tabular}


There was no sex related significant difference of contamination in the study subjects. Though the female HCP have a slight higher microbial growth. After taking all the samples from four infectious departments and make sensitivity to 40 random samples. The results showed that the overall susceptibility of the isolated gram-negative and gram positive to antimicrobial agents, the most effective antibiotic was found to be Imipenem was the most effective antibiotic.

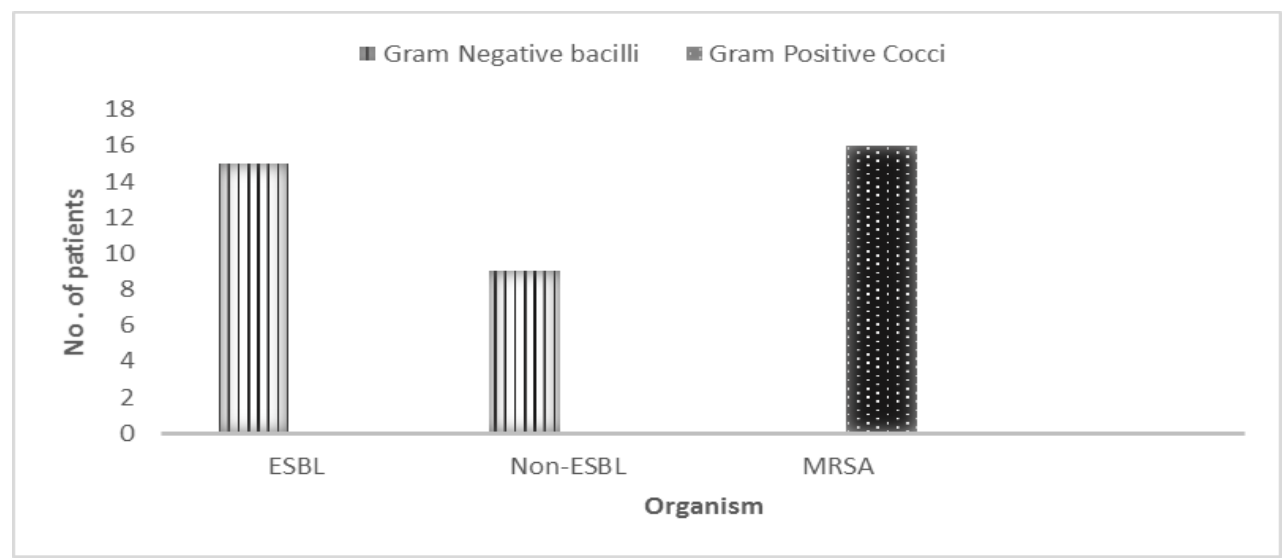

Figure (3): total no. of patients MRSA and ESBL among all departments MRSA: Methicillin Resistant Staphylococcus Aureus, ESBL: Extended Spectrum Beta Lactamase producing bacteria

It was found that from 40 different random cultures include nasal, axilla, vaginal, urine, wound and bedsore there are 24 cultures yielded significant gram negative bacilli growth indicative of infection divided into 15 cultures detected as ESBL and the other 9 cultures is non-ESBL while the other 16 
cultures yielded gram positive cocci growth all were indicative of MRSA infection.

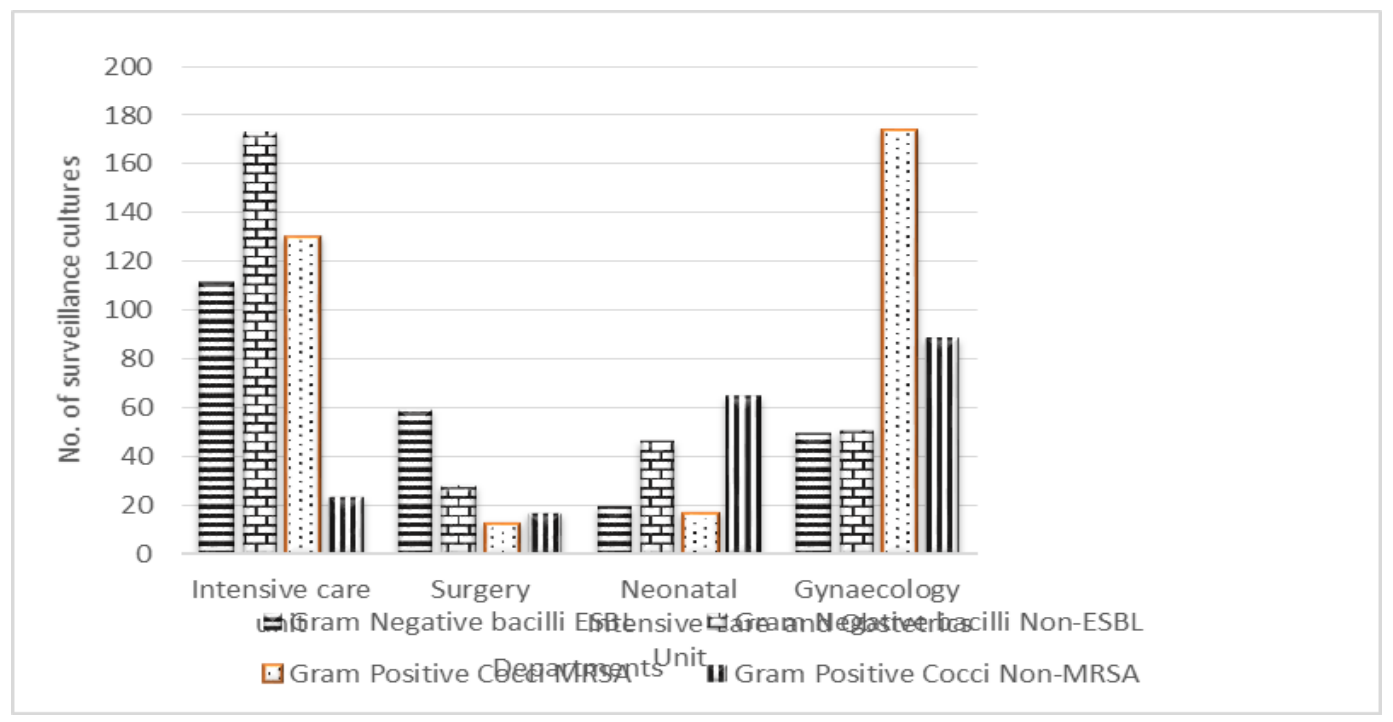

Figure (4): total result Methicillin Resistant Staphylococcus Aureus and Extended Spectrum Beta Lactamase among all departments MRSA: Methicillin Resistant Staphylococcus Aureus, ESBL: Extended Spectrum Beta Lactamase producing bacteria

Figure 4 showed that the two most infectious departments were Gynaecology and Obstetrics, ICU followed by Neonate Intensive Care Unit then the least infectious department compared to the previous departments was Surgery Departments. 
Journal of Environmental Sciences (JES)

Institute of Environmental Studies and Research, Ain Shams University

Abd Rabu, Nermeen et al.

Surface Results: A total of 507 surveillance cultures (SC) were taken after cleaning from ICU and another three infectious diseases department: Neonatal Intensive Care unit (NICU), Surgery department (SD), Gynaecology and Obstetrics department (GOD) recently occupied or used by patients infected or colonized.

Intervention Period: The 6-month intervention period lasted from one April to 31 September 2017. At the start of the intervention period, all environmental services staff, managers, and supervisors were fully informed of the study. The intervention involved 3 components: (1) a change in the application of disinfectant, (2) environmental services staff education on transmission of healthcare-associated pathogens and resultant infection, and (3) feedback regarding the thoroughness of room surface cleaning, the surface environment in rooms of colonized or infected patients is most frequently contaminated surfaces with many species which can survive on inanimate surfaces even for months. These species are found among the most frequent isolates from patients with healthcare associated infections. 
Table (4): The type and number of surveillance cultures (SC) taken from surfaces sent for the detection

\begin{tabular}{|c|c|c|c|c|c|c|}
\hline \multicolumn{6}{|c|}{$\begin{array}{l}\text { From } 1 \text { April to } 31 \text { September } \\
\text { Surface type/Total No. of places }\end{array}$} & \multirow{3}{*}{ Total } \\
\hline \multirow{3}{*}{$\begin{array}{c}\text { Place / } \\
\text { Department }\end{array}$} & \multirow{3}{*}{ Organism } & ICU & NICU & SD & GOD & \\
\hline & & \multicolumn{4}{|c|}{ Total } & \\
\hline & & 139 & 97 & 163 & 108 & 507 \\
\hline \multirow{2}{*}{ Beds } & "Gram negative bacilli & 16 & 14 & 12 & 11 & 53 \\
\hline & Gram positive cocci & 20 & 3 & 45 & 9 & 77 \\
\hline \multirow{2}{*}{ Wardrobe } & Gram negative bacilli & 13 & $\mathbf{0}$ & 22 & 10 & 45 \\
\hline & Gram positive cocci & 11 & 17 & 15 & 20 & 63 \\
\hline \multirow{2}{*}{ Bedside table } & Gram negative bacilli & 8 & $\mathbf{0}$ & 17 & 15 & 40 \\
\hline & Gram positive cocci & 7 & 13 & 9 & $\mathbf{0}$ & 29 \\
\hline \multirow{2}{*}{$\begin{array}{c}\text { Monitor touch } \\
\text { pad }\end{array}$} & Gram negative bacilli & 5 & 5 & 2 & 1 & 13 \\
\hline & Gram positive cocci & 12 & 7 & 17 & 1 & 37 \\
\hline \multirow{2}{*}{ Saline stand } & Gram negative bacilli & 3 & $\mathbf{0}$ & 1 & 5 & 9 \\
\hline & Gram positive cocci & 25 & 20 & 10 & 10 & 65 \\
\hline \multirow{2}{*}{ Walls } & Gram negative bacilli & 2 & $\mathbf{0}$ & 9 & 3 & 14 \\
\hline & Gram positive cocci & $\mathbf{0}$ & $\mathbf{0}$ & $\mathbf{0}$ & $\mathbf{0}$ & $\mathbf{0}$ \\
\hline \multirow{2}{*}{ Main Counter top } & Gram negative bacilli & 1 & $\mathbf{0}$ & $\mathbf{0}$ & $\mathbf{1}$ & 2 \\
\hline & Gram positive cocci & 3 & 18 & 3 & 19 & 43 \\
\hline \multirow{2}{*}{$\begin{array}{c}\text { Breathing circuit } \\
\text { interface and } \\
\text { patient port }\end{array}$} & Gram negative bacilli & 1 & $\mathbf{0}$ & $\mathbf{0}$ & $\mathbf{0}$ & 1 \\
\hline & Gram positive cocci & $\mathbf{0}$ & $\mathbf{0}$ & $\mathbf{0}$ & $\mathbf{0}$ & $\mathbf{0}$ \\
\hline \multirow{2}{*}{ Equipment cart } & Gram negative bacilli & 2 & $\mathbf{0}$ & 1 & 3 & 6 \\
\hline & Gram positive cocci & 10 & $\mathbf{0}$ & $\mathbf{0}$ & $\mathbf{0}$ & 10 \\
\hline \multirow{2}{*}{ Total } & Gram negative bacilli & 51 & 19 & 64 & 49 & 183 \\
\hline & Gram positive cocci & 88 & 78 & 99 & 59 & 324 \\
\hline
\end{tabular}




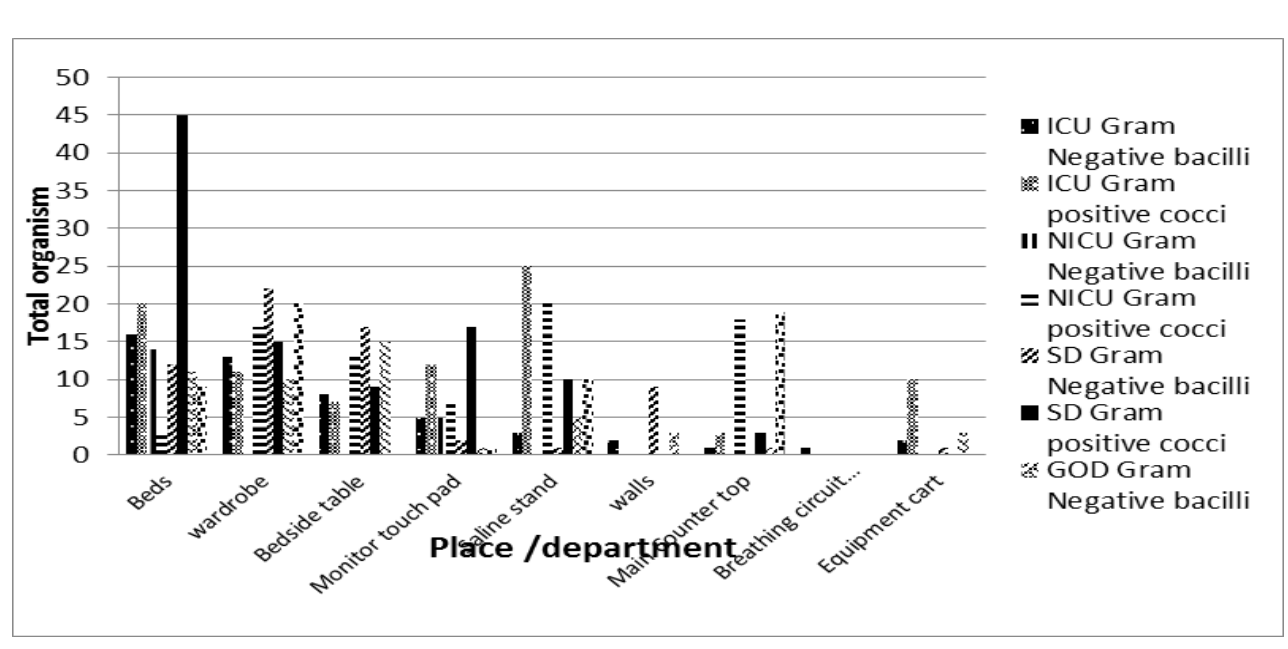

Figure (5): distributions of contaminated surfaces by cultured bacteria among surveyed departments

ICU: Intensive care unit, SD: Surgery Department, GOD: Gynecology and Obstetrics Department, NICU: Neonate Intensive Care Unit

The figure showed that most gram-positive bacteria (including MRSA) were monitored on Surgery department beds, which is survive for months on dry surfaces. Many gram negative species, can survive on inanimate surfaces even for months. These species are found among the most frequent isolates from patients with HCAIs. Overall, gram negative bacteria have been described to persist longer than gram-positive bacteria. Humid conditions improved persistence for most types of bacteria, or other relevant pathogens. Only staphylococcus aureus was found to persist longer at low humidity. Low temperatures, e.g., $4^{\circ} \mathrm{C}$ or $6^{\circ} \mathrm{C}$, also improved persistence of most types of bacteria such as MRSA. 
Journal of Environmental Sciences (JES)

Institute of Environmental Studies and Research, Ain Shams University

Abd Rabu, Nermeen et al.

\section{DISCUSSIONS}

Bacterial contamination is a serious problem in the hospital, especially in surgical practice where the site of sterile operation can become contaminated and subsequently infected (Wayne, 2001).

The study aimed to establish the appropriate number of surveillance cultures and appropriate combination of surveillance cultures to detect patients colonized or infected with the MRSA and ESBL. The study demonstrated that among 1071 cultures taken from ICU, Surgery, NICU and GOD, 529 gram positive cocci and 542 gram negative bacilli. We found a high prevalence of pathogenic bacteria $31.1 \%$ was positive for MRSA and $22.5 \%$ were positive for ESBL.

Schwaber et al., (2007) conducted a meta-analysis of 16 studies focused on comparing ESBL producing and non-ESBL producing Enterobacteriaceae, and the results revealed an almost twofold increase in mortality and five times more often a delay in appropriate antibiotic therapy in the ESBL positive patients. However, some of the studies included in the meta-analysis did not show any such difference, but the mortality rates were too low to provide statistical significance (i.e., $20 \%$ and $34 \%$ for the patients carrying non-ESBL producers and ESBL producers, respectively). Nearly the same results have been obtained in many other investigations demonstrated that inadequate antibiotic therapy and mortality were higher in the patients infected with ESBL producing strains of both K. pneumonia and E. coli. 
Journal of Environmental Sciences (JES)

Institute of Environmental Studies and Research, Ain Shams University

Abd Rabu, Nermeen et al.

In Denmark, a study was undertaken in four hospitals to establish the prevalence of MRSA and ESBL carriage in a Danish population of patients show that the MRSA strains isolated from nasal swabs were $59.5 \%$ (Halablab, et al., 2010). In 2006, a study was conducted in St. John Hospital and medical center in USA, the colonized patients were 33\% (65\% MRSA, 35\% ESBL) (Johnson, et al., 2009). In Saudi Arabia , a study was conducted in king Fahd Hospital and tertiary care center, involving end stage renal disease patients that showed about $38.05 \% \mathrm{~S}$. aureus nasal carriage was observed including (10.7\% MRSA and 27.3\% ESBL) (Saxena, et al., 2004).

In this study from 439 cultures taken from ICU of 208 patients who had paired nasal, axillary, wound, throat and bedsore cultures, 154 gram positive cocci and 285 gram negative bacilli were obtained. $29.6 \%$ were positive for MRSA and $25.5 \%$ were positive for ESBL.

From 119 cultures taken from Surgery, 30 Gram positive cocci and 89 Gram negative bacilli were obtained. $10.9 \%$ were positive for MRSA and $51.2 \%$ were positive for ESBL.

From 149 cultures taken from NICU, 82 Gram positive cocci and 67 gram negative bacilli were obtained. $11.4 \%$ were Positive for MRSA and 13.4 were positive for ESBL, and from 364 cultures taken from GOD, 174 gram positive cocci and 50 gram negative bacilli. $47.8 \%$ were positive for MRSA and $13.7 \%$ were positive for ESBL.

The Canadian ICU study was the first national, prospective surveillance study assessing antimicrobial resistance in patients in ICUs in Canada. This 
Journal of Environmental Sciences (JES)

Institute of Environmental Studies and Research, Ain Shams University

Abd Rabu, Nermeen et al.

national surveillance study involving 19 medical centers in major population centers in 9 of the 10 provinces in Canada found that $80 \%$ of all isolates recovered from clinical specimens in the ICUs were MRSA (Esposito, et al., 2007).

Considering that the above-mentioned studies showed that inadequate empirical therapy led to longer length of stay (LOS), and LOS has the greatest impact on the costs of bacteraemic episodes. In addition, the clinicians have to use more expensive antibiotic therapies, and, due to the high rate of co-resistance, it is not unusual that patients require parenteral therapy during the entire antibiotic regimen. Lautenbach, et al., (2001) found that infections with ESBL producing bacteria, E. coli and K. pneumoniae entailed a 2.9 times higher cost compared to infections with non ESBL producing strains, and other studies have indicated 1.5-1.7 times higher costs (Schwaber, et al., 2007 and Lee, et al., 2006). In 2006, the costs related to resistant bacteria were estimated to be an incredible $€ 900$ million in the European Union, and since then the rates have risen even further, and bacteria exhibiting even more problematic resistance have been found (Lee, et al., 2006).

Higher rates of antimicrobial resistance are expected in the ICU due to multiple factors, including increased use of high occurrence of invasive procedures, broad-spectrum antimicrobials, and increased chance of transmission of resistant bacteria among patients (Esposito and Leone, 2007) 
Journal of Environmental Sciences (JES)

Institute of Environmental Studies and Research, Ain Shams University

Abd Rabu, Nermeen et al.

The rapid increase of antibiotic-resistant bacteria, such as ESBL and MRSA, which threatens the treatment of common infections, has become a growing public health threat. Today, ESBL-producing bacteria and MRSA constitute a growing problem for healthcare facilities and for society. However, it is important to emphasize that independent of context the issue concerns human beings. It is humans who become carriers of ESBL and MRSA; it is humans who may spread the contagion; it is humans who become ESBL and MRSA patients and humans who care for those patients in healthcare facilities. In addition to, Several key hospital acquired pathogens (i.e., MRSA, VRE, Acinetobacter spp., norovirus, and C. difficile) have been demonstrated to persist in the environment for hours to days (and in some cases months), to frequently contaminate the surface environment and medical equipment in the rooms of infected or colonized patients, to transiently colonize the hands of HCP, to be associated with person to person transmission via the hands of $\mathrm{HCP}$, and to cause outbreaks in which environmental transmission was deemed to play a role. Furthermore, hospitalization in a room in which the previous patient had been infected or colonized with MRSA, ESBL, VRE, C. difficile, multi drug resistant Acinetobacter spp., or multidrug-resistant Pseudomonas has been shown to be a risk factor for infection or colonization with the same pathogen for the next patient admitted to the room. The implementation of checklists, enhanced education, and methods to measure the effectiveness of room cleaning with immediate feedback to environmental service personnel has been found to 
Journal of Environmental Sciences (JES)

Institute of Environmental Studies and Research, Ain Shams University

Abd Rabu, Nermeen et al.

improve cleaning and lead to a reduction in hospital acquired infections. (Ajao, et al., 2013).

\section{CONCLUSION}

Sources of infection in a hospital are numerous and a variety of infectious agents are involved which cause infections ranging from mild to lifethreatening. It is necessary to identify them and understand their mode of transmission so that effective preventive and control measures can be undertaken. Inanimate surfaces and equipment in ICU are heavily contaminated by bacteria, including multi drug resistant species. Bacterial contamination may contribute to ICU-acquired colonization or infection, but further studies are needed to evaluate this correlation. Clinicians and researchers should be aware of the risk of cross transmission of pathogens from inanimate surfaces in order to adopt appropriate infection control measures.

\section{RECOMMENDATIONS}

In light of the results and discussion presented in this study, the following recommendations are made:

- The high prevalence rate of MRSA and ESBL among patients necessitates the screening approach for all hospitals to provide antibiotic prophylaxis to MRSA and ESBL carrier. 
- It is important to eradicate MRSA and ESBL colonization in both patients and $\mathrm{HCP}$ to prevent its spread to the community.

- Use of personal protective equipment specially masks by all HCP when they are in direct contact with patients.

- Antibiotic resistant MRSA and ESBL may occur as a result of misuse or overuse of antibiotics. Therefore, health care providers worldwide should be encouraged to join public health authorities, to control the inappropriate use of antibiotics and promote responsible prescribing. This will greatly help to improve prevention and control of drug resistant organisms in communities.

- It is recommended to conduct more studies with larger sample size covering larger number of healthcare facilities which will impact the management of healthcare associated infection

- Formulate guidelines for the MRSA and ESBL screening policy in Egypt.

- Rational antibiotic prescribing based on local guidelines to prevent the development of bacterial resistance.

\section{REFERENCES}

Allegranzi B. (2011): Burden of endemic health care-associated infection in developing countries: systematic review and meta-analysis. Lancet, 2011, 377:228-241. 
Ajao AO; Johnson JK; Harris AD et al. (2013): Risk of acquiring extendedspectrum b-lactamase-producing Klebsiella species and Escherichia coli from prior room occupants in the intensive care unit. Infect Control Hosp Epidemiol; 34:453-458.

Bates D.W. (2009): Global priorities for patient safety research. British Medical Journal, 338:b1775.

Burke JP. (2003): Infection control - a problem for patient safety. New England Journal of Medicine, 348:651-656.

Cevik MA (2005): Relationship between nosocomial infection and mortality in a neurology intensive care unit in Turkey. Journal of Hospital Infection, 2005, 59:324-330.

De Gentile A. (2001): Nosocomial infections in a children's hospital in Argentina: impact of a unique infection control intervention program. Infection Control and Hospital Epidemiology, 22:762766.

Esposito, S., and S. Leone (2007): Antimicrobial treatment for intensive care unit (ICU) infections including the role of the infectious diseases specialist. Int. J. Antimicrob. Agents 29:494-500.

Gravel D. (2007): Point prevalence survey for healthcare-associated infections within Canadian adult acute-care hospitals. Journal of Hospital Infection, 2007, 66:243-248.

Halablab MA; Hijazi SM; Fawzi MA; Araj GF. (2010): May. Staphylococcus aureus nasal carriage rate and associated risk factors in individuals in the community. Epidemiology and Infection. 138(5):702-6.

Hanberger H, Arman D, Gill H, Jindrak V, Kalenic S, Kurcz A, et al.: Surveillance of microbial resistance in European Intensive Care Units: a first report from the Care-ICU programme for improved infection control. Intensive Care Med 2009; 35: 91-100. 
Horan TC; Andrus M and Dudeck MA. (2008): CDC/NHSN surveillance definition of health care-associated infection and criteria for specific types of infections in the acute care setting. American Journal of Infection Control, 36:309-332.

Johnson LB.; Jose J.; Yousif F.; Pawlak J. and Saravolatz LD. (Jan. 2009): Prevalence of colonization with community-associated methicillinresistant Staphylococcus aureus among end-stage renal disease patients and healthcare workers. Infect Control Hosp Epidemiol. 30(1):48.

Festary A, Kouri V, Correa CB, Verdasquera D, Roig T, Couret MP. (2015): Cytomegalovirus and herpes simplex infections in mothers and newborns in a Havana maternity hospital. MEDICC Rev, 2015; 17: 29-34.

Lanini S. (2009): Healthcare-associated infection in Italy: annual pointprevalence surveys, 2002-2004. Infection Control and Hospital Epidemiology, 30:659-665.

Lautenbach E, Patel JB, Bilker WB, Edelstein PH, Fishman NO. (2001): Extended-spectrum beta-lactamase producing Escherichia coli and Klebsiella pneumoniae: risk factors for infection and impact of resistance on outcomes. Clin Infect Dis2001 Apr 15; 32(8):1162-71.

Leape LL and Berwick DM. (2005): Five years after To Err is Human: what have we learned? JAMA; 293:2384-90.

Leape LL.: Reporting of adverse events. N Engl J Med" "2002" ; 347:16338.

Lee SY; Kotapati S.; Kuti JL.; Nightingale CH. and Nicolau DP. (2006): Impact of extended spectrum beta-lactamase-producing Escherichia coli and Klebsiella species on clinical outcomes and hospital costs: a matched cohort study. Infect Control Hosp Epidemiol Nov; 27(11):1226-32. 
Saxena AK.; Panhotra BR. and Chopra R. (Sep-Oct. 2004): Advancing age and the risk of nasal carriage of Staphylococcus aureus among patients on long-term hospital-based hemodialysis. Annal of Saudi Medicine. 24(5):337-42

Schwaber MJ, Navon-Venezia S, Kaye KS, Ben-Ami R, Schwartz D, Carmeli Y. (2007): Clinical and economic impact of bacteremia with extended-spectrum-beta-lactamase producing Enterobacteriaceae. Antimicrob Agents Chemother. Apr; 50(4):1257- 62.

Wayne (2001): National Committee for clinical laboratory standards performance for antimicrobial susceptibility testing. $11^{\text {th }}$ edition.

World Health Organization and International Programmed on Chemical Safety (2002): Global Assessment of the world Health Organization Guideline for Drinking Water Quality Recommendation. 


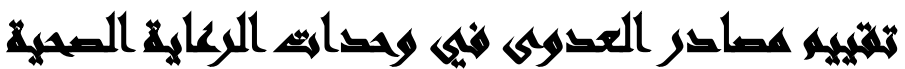

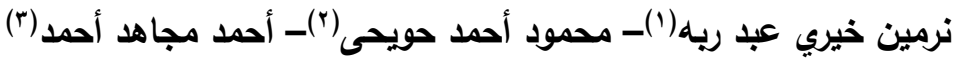

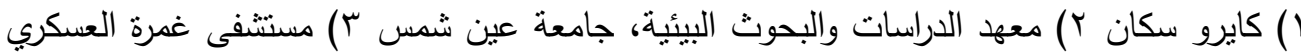 \\ للعائلات الترو
}

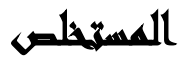

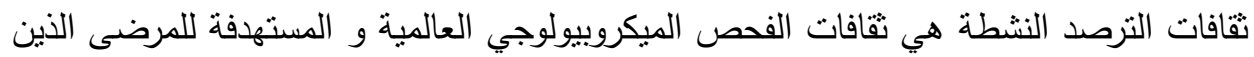

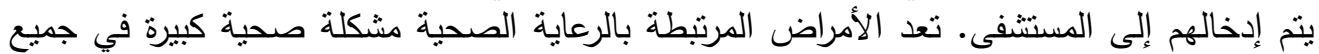

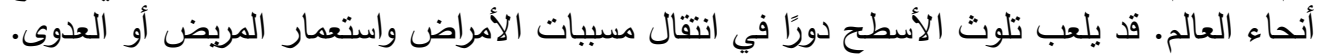

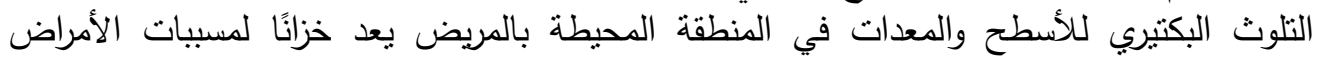

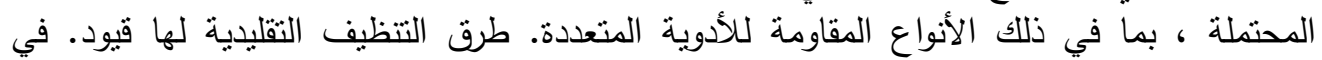

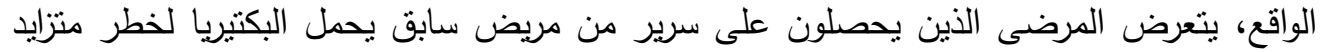

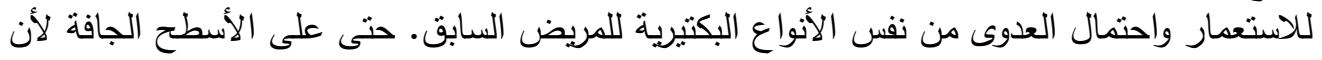

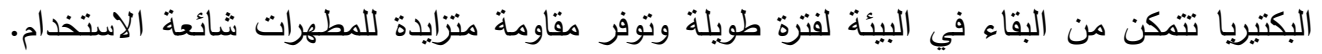

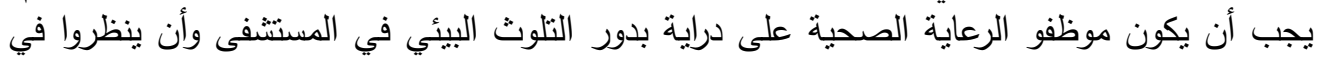

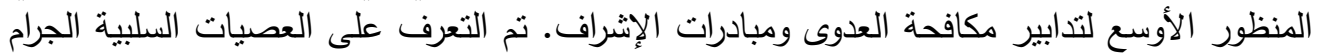

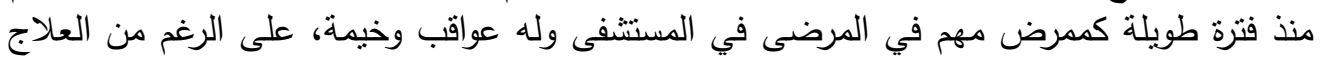

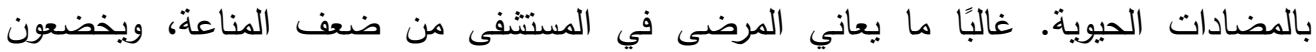
لفحوصات وعلاجات كثيرة، وقد تسهل ممارسات رعاية المرضى وبيئة المسنتفى انتقال الكائنات

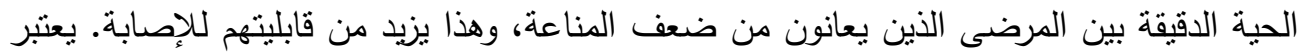

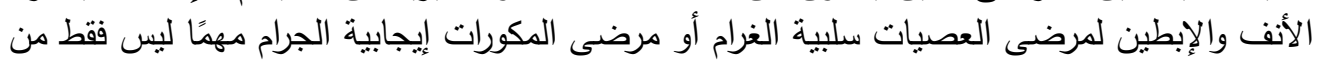

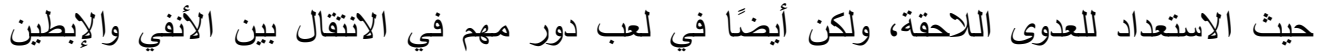

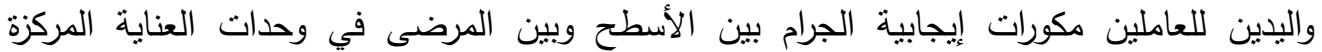

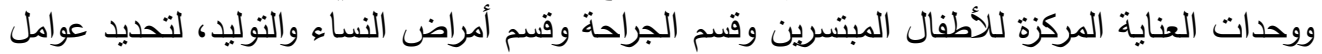

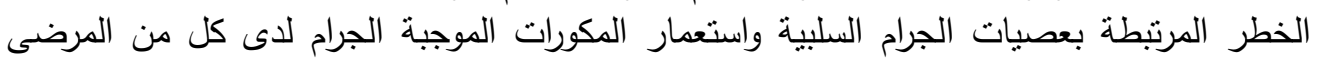

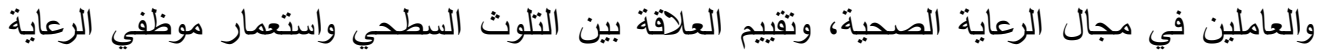

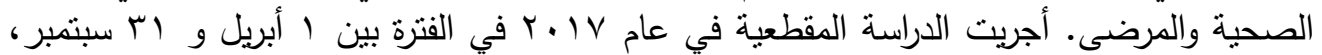

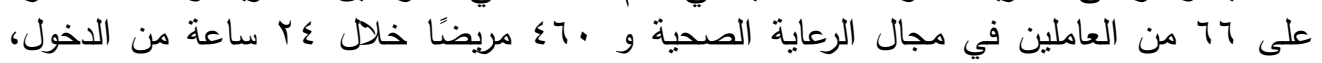


Journal of Environmental Sciences (JES)

Institute of Environmental Studies and Research, Ain Shams University

Abd Rabu, Nermeen et al.

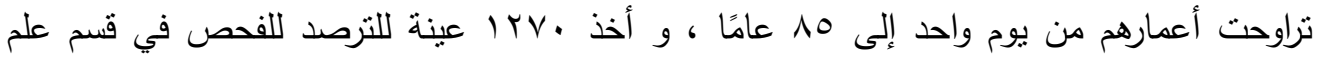

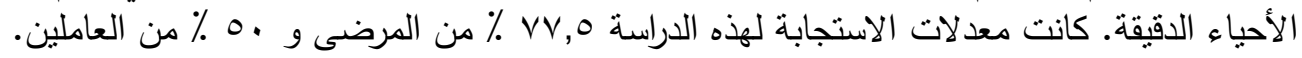

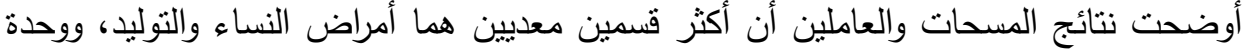

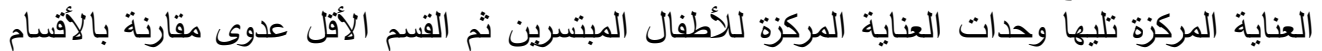

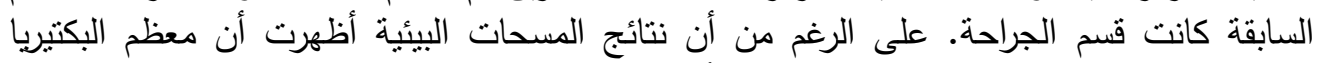

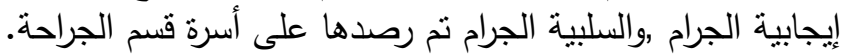
الكلمات الالية: الأمراض المرتبة بالرعاية الصحية، البكتبريا إيجابية الجرام، البكتيريا السلبية الجرام، حساسية المضادات الحيوية. 